\title{
Аномальные фотоэлектрические явления в кремнии с нанокластерами атомов марганца
}

\author{
(C) М.К. Бахадирханов ${ }^{1}$, С.Б. Исамов ${ }^{1}$, Н.Ф. Зикриллаев ${ }^{1}$, М.О. Турсунов $^{2}$ \\ ${ }^{1}$ Ташкентский государственный технический университет, \\ 100095 Ташкент, Узбекистан \\ 2 Термезский государственный университет, \\ 190111 Термез, Узбекистан \\ E-mail: sobir-i@mail.ru
}

Поступила в Редакцию 27 сентября 2020 г.

В окончательной редакции 15 февраля 2021 г.

Принята к публикации 19 февраля 2021 г.

\begin{abstract}
Показано, что в кремнии с нанокластерами атомов марганца наблюдается ряд аномальных фотоэлектрических явлений, таких как примесная остаточная фотопроводимость с большим временем релаксации, инфракрасное гашение фотопроводимости при отсутствии собственного фонового света, гигантская примесная фотопроводимость и примесная суперлинейная ватт-амперная характеристика, связанные с наличием нанокластеров атомов марганца. Природу этих явлений невозможно объяснить существующей теорией фотопроводимости. Такие материалы могут быть использованы для создания новых типов фотоэлектрических приборов.
\end{abstract}

Ключевые слова: кремний, марганец, нанокластер, ИК гашение, фотопроводимость, фотоотклик.

DOI: 10.21883/FTP.2021.06.50912.9259

\section{1. Введение}

Исследование свойств полупроводниковых материалов с кластерами примесных атомов представляет большой научный и практической интерес [1-5]. Это связано с тем, что примесные атомы в кластере, согласно принципу Паули, не могут иметь те же энергетические уровни (и другие свойства), что и в атомарном состоянии. Кластеры могут действовать как квантовые точки - нанообъекты, обладающие не только особой энергетической структурой, но и существенно влияющие на фундаментальные параметры основного материала. В этом плане представляют интерес кластеры атомов марганца, состоящие из четырех атомов, находящихся в ближайших межузельных положениях вокруг атома бора. Наличие таких кластеров экспериментально доказано многими авторами [6-10]. В работе [11] нами был описан новый способ легирования кремния марганцем, позволяющий получить максимальное участие введенных атомов в процессе формирования кластеров. Авторы работ [11-13] показали, что в кремнии с кластерами атомов марганца наблюдается ряд новых магнитных и фотомагнитных явлений, которые отсутствуют не только в кремнии, легированном марганцем без образования кластеров, но и в других магнитных полупроводниках.

В данной работе рассмотрены аномальные фотоэлектрические явления в кремнии с нанокластерами атомов марганца, которые трудно объяснить существующей теорией фотопроводимости [14] и метастабильностью свойств глубоких центров вследствие взаимосвязанности электрон-колебательного взаимодействия и зарядовых корреляций $[15,16]$. Эти результаты показывают, что на основе такого материала можно создать новые типы фотоэлектрических приборов.

\section{2. Технология и метод исследования}

Легирование кремния марганцем проводилось по разработанной нами технологии [17], позволяющей формировать нанокластеры, охватывающие практически все введенные атомы марганца.

В качестве исходного материала был использован монокристаллический кремний с $\rho \sim 5 \mathrm{OM} \cdot \mathrm{cm} \quad\left(N_{\mathrm{B}}=4 \cdot 10^{15} \mathrm{~cm}^{-3}\right), \quad$ с концентрацией кислорода $\quad N_{\mathrm{O}_{2}}=(6-7) \cdot 10^{17} \mathrm{~cm}^{-3} \quad$ и плотностью дислокаций $\sim 10^{3} \mathrm{~cm}^{-2}$. Размеры образцов составляли $8 \times 3 \times 0.8 \mathrm{MM}$.

Условия диффузионного легирования выбирались таким образом, чтобы получить после легирования образцы $p$-типа проводимости с $\rho=10^{3}-10^{4} \mathrm{OM} \cdot \mathrm{cм}$, так как в таких образцах наблюдается самая высокая фоточувствительность.

Диффузия марганца проводилась из газовой фазы при температуре $T=1075-1080^{\circ} \mathrm{C}$ в течение 7-90мин с последующим резким охлаждением. После диффузии поверхность образцов подвергалась необходимым механической и химической обработкам для удаления низкоомного поверхностного слоя. Электрические параметры образцов исследовались методом эффекта Холла (см. таблицу).

Как видно из данной таблицы, все образцы после диффузии сохраняли тип проводимости, но их удельное сопротивление возрастало до $(3-8) \cdot 10^{3} \mathrm{OM} \cdot \mathrm{cm}$. Как показывают расчеты, в исследуемых образцах положения уровней Ферми $\left(E_{\mathrm{F}}\right)$ находятся в диапазоне $\left(E_{V}+0.31\right)-\left(E_{V}+0.49\right)$ эВ. Если учесть, что атомы марганца в кремнии создают два донорных уровня $\mathrm{c}$ энергией ионизации $E_{1}=E_{C}-0.27$ эВ и 
Электрические параметры образцов, измеренные по эффекту Холла

\begin{tabular}{c|c|c|c|c}
\hline $\begin{array}{c}\rho, \\
\text { Ом } \cdot \text { см }\end{array}$ & $\begin{array}{c}\text { Тип } \\
\text { проводимости }\end{array}$ & $\begin{array}{c}\mu, \\
\mathrm{cm}^{2} / \mathrm{B} \cdot \mathrm{c}\end{array}$ & $\begin{array}{c}N, \\
\mathrm{~cm}^{-3}\end{array}$ & $\begin{array}{c}E_{\mathrm{F}}, \\
\text { эВ }\end{array}$ \\
\hline $4-0 \cdot 10^{3}$ & $p$ & 120 & $1-30 \cdot 10^{13}$ & $E_{V}+0.363$ \\
$5-6 \cdot 10^{3}$ & $p$ & 86 & $1-30 \cdot 10^{13}$ & $E_{V}+0.363$ \\
$6-2 \cdot 10^{3}$ & $p$ & 72 & $1-40 \cdot 10^{13}$ & $E_{V}+0.361$ \\
$8-0 \cdot 10^{3}$ & $p$ & 63 & $1-24 \cdot 10^{13}$ & $E_{V}+0.364$
\end{tabular}

$E_{2}=E_{C}-0.5$ эВ [10], то можно утверждать, что в исследуемых образцах оба уровня марганца практически свободны от электронов. Это означает, что все введенные атомы марганца в решетке кремния находятся в состоянии $\mathrm{Mn}^{++}$.

Фотоэлектрические свойства образцов исследовались с использованием спектрометра ИКС-21. Образцы помешались в криостат, позволяющий исследовать фотопроводимость в широком интервале температур $T=77-320 \mathrm{~K}$, электрического поля $E=1-100 \mathrm{~B} / \mathrm{cm} \mathrm{и}$ спектральной области $\lambda=1-8$ мкм. Перед окошком криостата были установлены фильтры из полированного монокристаллического кремния толщиной 380 мкм, что обеспечивало отсутствие коротковолнового рассеянного и фонового излучений. Мощность падающего излучения в исследуемой области спектра поддерживалась постоянной с помощью калиброванных сетчатых фильтров.

\section{3. Результаты исследования}

При исследовании фотоэлектрических свойств исследуемых образцов были обнаружены следующие аномальные явления, которые отсутствуют в обычных фоточувствительных полупроводниковых материалах.

1. „Примесная“ остаточная фотопроводимость с аномально медленной релаксацией.

На рис. 1 представлены кривые релаксации фототока после выключения освещения с энергией фотонов $h v=0.16,0.22$ и 0.50 эВ, т.е. примесного света, соответственно с $\lambda=7.75 ; 5.6$ и 2.4 мкм. Как видно из рисунка, достаточно высокое значение примесного фототока, возникающего при освещении образцов, после выключения света практически остается без существенных изменений достаточно долгое время, т.е. наблюдается остаточная проводимость (ОП) с очень большим временем релаксации, вызванная „примесным“ светом.

Согласно существующей теории фотопроводимости, ОП в полупроводниках $[14,18]$ возникает при освещении материала светом с энергией фотона $h v>E_{g}$, т. е. при фотогенерации носителей заряда собственным светом. При этом фотогенерируемые носители заряда, из-за их захвата пространственно разделенными глубокими центрами, после прекращения фотогенерации рекомбинируют очень медленно [19].

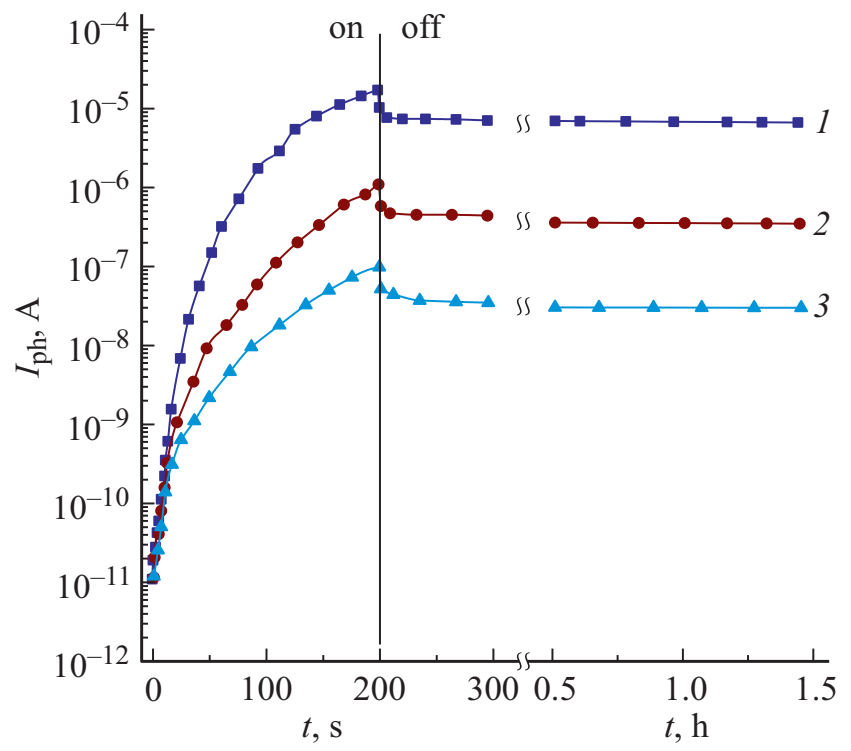

Рис. 1. Зависимость фототока от времени в процессе включения (on) и отключения (off) освещенности падающего ИК излучения для образцов $\mathrm{Si}\langle\mathrm{B}, \mathrm{Mn}\rangle$ при $T=180 \mathrm{~K}$ и одинаковой интенсивности с разной энергией фотонов, $h v: 1-0.50$, $2-0.22,3-0$ эВ.

В данном эффекте „примесной“ ОП имеются существенные отличия от обычной ОП:

- ОП возникает в отсутствие освещения собственным светом (только при освещении примесным светом в области $\lambda=2.74-7.77$ мкм).

- ОП не связана с фотогенерацией носителей примесными центрами атомов марганца в кремнии, так как в исследуемых материалах оба донорных уровня марганца практически не заняты электронами. Поэтому можно предполагать, что электроны переходят из валентной зоны на энергетические состояния кластеров атомов марганца.

- Релаксация ОП происходит аномально медленно, что говорит об очень сильной анизотропии сечений захвата электронов и дырок центрами, структура и происхождение которых связаны только с наличием кластеров марганца.

Полученные данные не только невозможно объяснить на основе существующей теории ОП, но и, насколько нам известно, еще ни в одном полупроводниковом материале не была обнаружена „примесная“ ОП с такой аномально большой постоянной времени релаксации.

2. ИК гашение фотопроводимости (ИКГ ФП)

Как известно, явление ИКГ ФП возникает при постоянном освещении образцов светом с энергией фотонов $h v>E_{g}$ (область собственной фотопроводимости) и дополнительном освещении образца ИК светом с определенной энергией фотонов [14], приводящем к перезарядке рекомбинационных и очувствляющих центров. Поэтому для наблюдения ИКГ ФП необходимо освещение образцов собственным светом в процессе измерения спектральной зависимости ФП. 


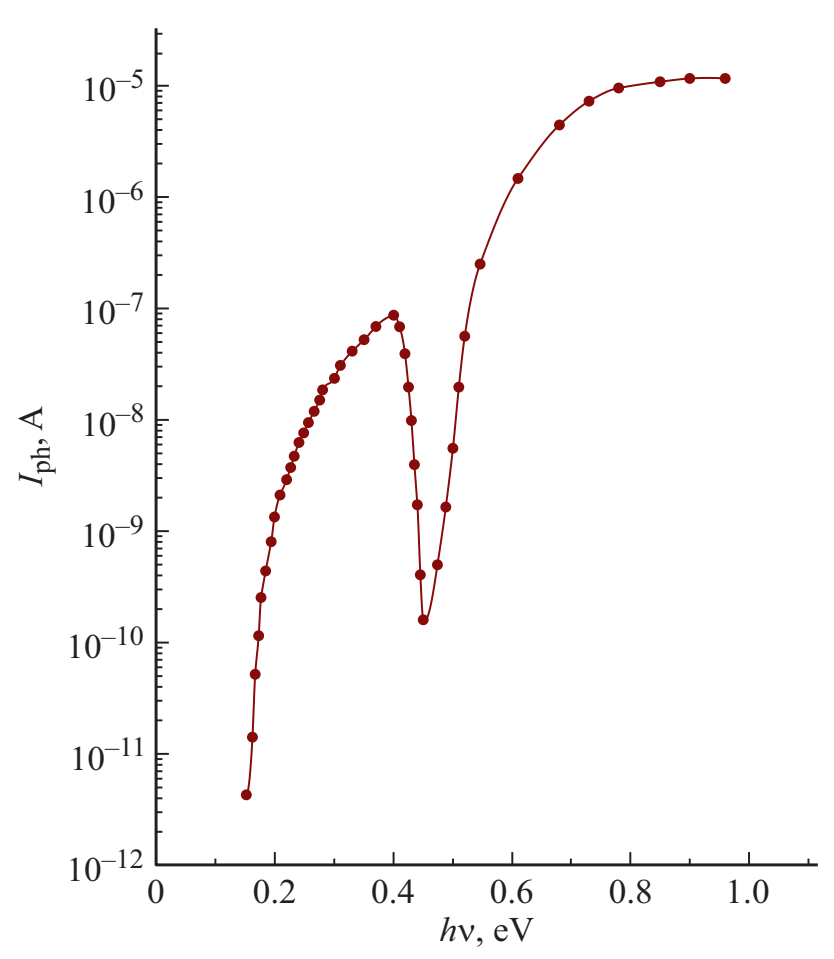

Рис. 2. Инфракрасное гашение фотопроводимости кремния с нанокластерами атомов марганца при $T=100 \mathrm{~K}$, $\rho=1 \cdot 10^{4} \mathrm{OM} \cdot \mathrm{cm}$.

На рис. 2 представлена спектральная зависимость фотопроводимости образцов при полном отсутствии фонового освещения „собственным“ светом. Как видно из рисунка, заметный фотоответ начинается при $h v \sim 0.16$ эВ, и его значение непрерывно и существенно увеличивается с ростом энергии падающего кванта. Этот процесс продолжается до максимума при $h v=0.4$ эВ. Дальнейшее увеличение энергии падающего фотона приводит к уменьшению фототока, т.е. наблюдается гашение. Фототок при этом уменьшается очень значительно (на 2.5-3 порядка), т. е. наблюдается гигантское примесное ИК гашение ФП. Начиная с $h v=0.45$ эВ фототок скачкообразно увеличивается и достигает своего максимального значения при $h v=0.73$ эВ, т. е. одновременно в этих образцах наблюдается и гигантское значение примесной фотопроводимости в области $h v=0.5-0.73$ эВ.

Это явление наблюдается во всех образцах с $\rho=(4-8) \cdot 10^{3}$ Ом · см. Согласно двухуровневой модели ИКГ ФП [14], за счет действия „собственного“ фонового света происходит фотогенерация носителей и перезарядка рекомбинационных и очувствляющих центров. В результате этого наблюдается эффект очувствления, т. е. материал будет обладать высокой фоточувствительностью. Дополнительное освещение образцов ИК светом с энергией фотонов, равной энергии ионизации очувствляющего центра, приводит к обратному процессу, в результате которого уменьшается $Ф П$, т.е. имеет место эффект ИКГ ФП.

В образцах с нанокластерами атомов марганца эффект ИКГ имеет следующие особенности.
- Наблюдается ИКГ ФП при отсутствии фонового света (только под действием ИК света с $h v=0.4$ эВ), это означает, что происходит генерация только одного типа носителей заряда - дырок в валентной зоне.

- ИКГ имеет место в достаточно узком интервале энергии фотонов ИК излучения $\Delta E=0.05$ эВ (от 0.45 до 0.4 эВ).

- Наблюдается скачкообразное и очень существенное увеличение фототока как до гашения, так и после.

Эти результаты показывают, что ИКГ ФП в исследуемых образцах имеет аномальный характер [20], который нельзя объяснить существующей теорией ИКГ ФП [14].

3. Ватт-амперная характеристика

Ватт-амперная характеристика (ВТАХ) образцов снималась при полном отсутствии фонового света, только при изменении мощности падающего ИК света с энергией фотонов $h v=0.33,0.50$ и 0.73 эВ. Полученные результаты представлены на рис. 3 .

Установлено, что в области достаточно низких мощностей $\left(W<8 \cdot 10^{-5} \mathrm{BT}\right)$ ИК излучения с энергией фотонов $h v=0.33$ эВ с ростом мощности излучения в интервале $W=10^{-8}-1.45 \cdot 10^{-6}$ Вт значение фототока увеличивается достаточно медленно и наблюдается сублинейная ВтАХ. Начиная с мощности $1.45 \cdot 10^{-6} \mathrm{BT}$ фототок резко увеличивается и достигает максимального значения при $1.34 \cdot 10^{-5}$ Вт. Величина фототока при этом увеличивается сразу на 4 порядка, т. е. имеет место суперлинейная ВтАХ. При дальнейшем росте мощности излучения также наблюдается сублинейная зависимость фототока.

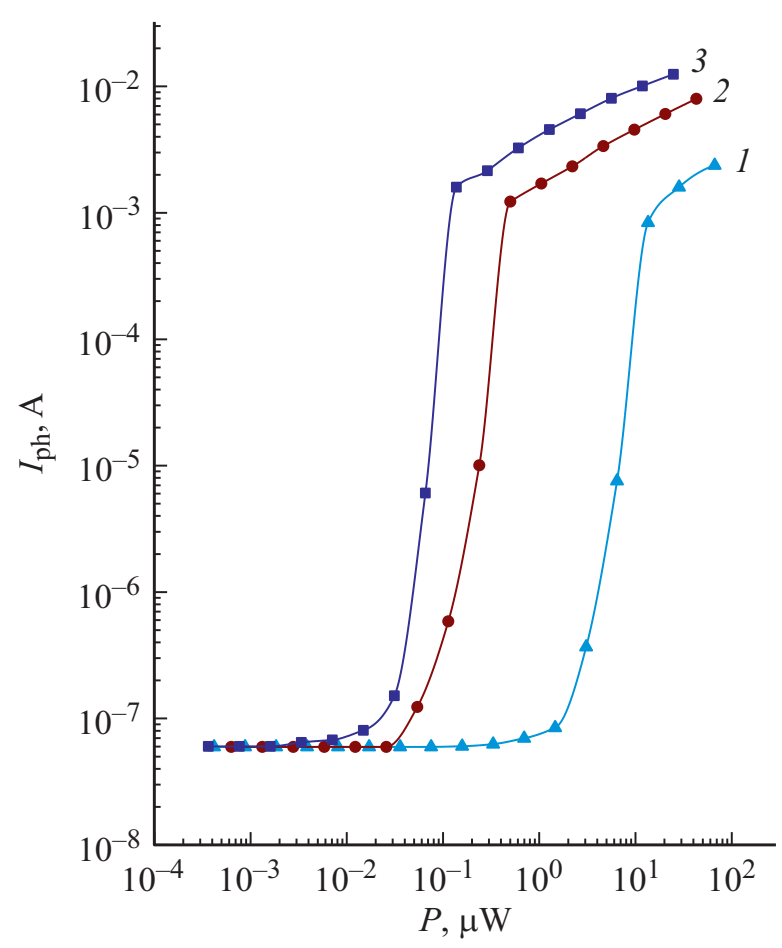

Рис. 3. Ватт-амперная характеристика образцов кремния с нанокластерами атомов марганца с разной энергией фотонов, $h v$ : $1-0.33,2-0.50,3-0.73$ эВ. 
С ростом энергии падающего фотона $(h v=0-50$ эВ $)$ начало суперлинейной ВТАХ (рис. 3, кривая 2) смещается в область меньшей мощности $-2 \cdot 10^{-7}$ Вт, что почти на 1 порядок меньше по сравнению с $h v=0-33$ эВ. Такая тенденция изменения ВтАХ имеет место и при дальнейшем росте энергии падающего фотона (кривая $3-h v=0-73$ эВ). Таким образом, в исследуемых образцах обнаружена примесная суперлинейная ВТАХ. В обычных фоточувствительных полупроводниковых материалах суперлинейная ЛАХ имеет место только при освещении фоновым собственным светом и объясняется эффектом очувствления [18], который связан с увеличением времени жизни фотоносителей заряда в результате перезарядки рекомбинационных и очувствляющих центров при освещении собственным светом.

В исследуемых образцах этот эффект наблюдается не только в отсутствие собственного света, но и при достаточно малой величине и узком интервале мощности ИК излучения. Поэтому этот эффект можно называть аномальным эффектом примесной суперлинейной ВтАХ, и он также трудно объясним на основе двухуровневых моделей фотопроводимости.

Обнаруженные новые аномальные фотоэлектрические явления, по нашему мнению, могут быть связаны только с наличием многозарядных центров в виде кластеров атомов марганца в решетке кремния, что приводит к существенным изменениям структуры энергетических состояний электронов. Для подтверждения этого требуются более детальные исследования.

\section{4. Заключение}

Обнаруженные новые аномальные фотоэлектрические свойства в кремнии с нанокластерами атомов марганца показывают, что формированием кластеров примесных атомов можно существенно изменять электрические, магнитные [11] и фотоэлектрические свойства материала, а также обнаружить в этих материалах ряд новых физических явлений, которые отсутствуют у обычных легированных полупроводниковых материалов. Для объяснения физических процессов этих аномальных явлений требуются более детальные исследования в зависимости от природы, структуры, состава и концентрации примесных кластеров. Полученные экспериментальные данные показывают, что кремний с кластерами атомов марганца является новым перспективным материалом, позволяющим создавать на его основе принципиально новые типы фотоэлектрических приборов.

\section{Конфликт интересов}

Авторы заявляют, что у них нет конфликта интересов.

\section{Список литературы}

[1] W. Ouyang, F. Teng, H. He, X. Fang. Adv. Funct. Mater., 1807672 (2019).

[2] R. Mainz, A. Singh, S. Levcenko, M. Klaus, C. Genzel, K.M. Ryan, T. Unold. Nature Commun., 5, 3133 (2014).
[3] N. Fukata. Adv. Mater., 21, 2829 (2009).

[4] M. Seibt, V. Kveder, W. Schröter, O. Voß. Phys. Status Solidi A, 202, 911 (2005).

[5] M.T. Björk, H. Schmid, J. Knoch, H. Riel, W. Riess. Nature Nanotech., 4, 103 (2009).

[6] M.K. Bakhadyrkhanov, K.S. Ayupov, G.Kh. Mavlyanov, S.B. Isamov. Semiconductors, 44 (9), 1145 (2010).

[7] J. Kreissl, W. Gehlhoff. Phys. Status Solidi B, 145, 609 (1988).

[8] Ш.И. Аскаров, М.К. Бахадирханов, В.Ф. Мастеров, В.Ф. Штельмах. ФТП, 16, 1308. (1982).

[9] J. Kreissl, W. Gehlhoff. Phys. Rev. B, 49, 10307 (1994).

[10] K.P. Abdurakhmonov, A.A. Lebedev, J. Kreissl, Sh.B. Utamuradova. Sov. Phys. Semicond., 19, 213 (1985).

[11] M.K. Bakhadyrkhanov, G.Kh. Mavlonov, S.B. Isamov, Kh.M. Iliev, K.S. Ayupov, Z.M. Saparniyazova, S.A. Tachilin. Inorg. Mater., 47, 5, 479 (2011).

[12] M.K. Bakhadyrkhanov, K.S. Ayupov, Kh.M. Iliev, G.Kh. Mavlonov, O.E. Sattorov. Techn. Phys. Lett., 35, 741 (2009).

[13] M.K. Bakhadyrkhanov, S.B. Isamov. Techn. Phys., 61, 458 (2016).

[14] А. Роуз. Основы теории фотопроводимости (М., ИЛ, 1962).

[15] N.T. Bagraev, V.A. Mashkov. Solid State Commun., 65, 1111 (1988).

[16] N.T. Bagraev, I.S. Polovtsev. Sov. Phys. - JETP Lett., 56, 35 (1992).

[17] Б.А. Абдурахманов, К.С. Аюпов, М.К. Бахадырханов, Х.М. Илиев, Д.Т. Бобонов, Н.Ф. Зикриллаев, 3.М. Сапарниязова, А. Тошев. Докл. АН РУ $, 4,32$ (2010).

[18] С.В. Рывкин. Фотоэлектрические явления в полупроводниках (М., Физматгиз, 1963).

[19] М.К. Шейнкман, А.Я. Шик. ФТП, 10, 209 (1976).

[20] С.Б. Исамов. Докл. АН Республики Узбекистан, 1, 23 (2016).

Редактор А.Н. Смирнов

\section{Anomalously photoelectric phenomena in silicon with nanoclusters manganese atoms}

\author{
M.K. Bakhadirkhanov ${ }^{1}$, S.B. Isamov ${ }^{1}$, N.F. Zikrillaev ${ }^{1}$, \\ M.O. Tursunov ${ }^{2}$ \\ ${ }^{1}$ Tashkent State Technical University, \\ 100095 Tashkent, Uzbekistan \\ 2 Termez State University, \\ 190111 Termez, Uzbekistan
}

Abstract It is shown that some anomalous photoelectric phenomena are observed in silicon with nanoclusters of manganese atoms, such: impurity residual photoconductivity with a long relaxation time, infrared quenching of photoconductivity in the absence of intrinsic background light, giant impurity photoconductivity, and impurity superlinear watt-ampere characteristic associated with the presence of nanoclusters manganese atoms. The nature of these phenomena cannot be explained by the existing theory of photoconductivity. Such materials can be used to create new types of photovoltaic devices. 